\title{
In vitro invasion efficiency and intracellular proliferation rate comprise virulence-related phenotypic traits of Neospora caninum
}

Javier Regidor-Cerrillo ${ }^{1 *}$, Mercedes Gómez-Bautista', Itsaso Sodupe², Gorka Aduriz², Gema Álvarez-García', Itziar Del Pozo², Luis Miguel Ortega-Mora'

\begin{abstract}
In this study, we examined the in vitro invasion and proliferation capacities of the Nc-Liv and ten Spanish Neospora caninum isolates (Nc-Spain $1 \mathrm{H}$ - Nc-Spain 10). The invasion rate was determined as the number of tachyzoites that completed their internalisation into MARC-145 cells at 2, 4, and $6 \mathrm{~h}$ post-inoculation (pi). The proliferation rate was evaluated by determining the doubling time during the exponential proliferation period. Significant differences in the invasion rates of these isolates were detected at 2 and $4 \mathrm{~h}$ pi $(P<0.0001$, Kruskal-Wallis test). At $4 \mathrm{~h}$ pi, the NcSpain $4 \mathrm{H}$ and Nc-Liv isolates displayed the highest, while the Nc-Spain $3 \mathrm{H}$ and Nc-Spain $1 \mathrm{H}$ isolates had the lowest invasion rates (by Dunn's test). Variations in the proliferation kinetics of these isolates were also observed. Between different isolates, the lag phase, which occurs before the exponential growth phase, ranged from 8 to 44 $\mathrm{h}$, and the doubling time ranged from 9.8 to $14.1 \mathrm{~h}$ ( $P=0.0016$, ANOVA test). Tachyzoite yield, which combines invasion and proliferation data, was also assessed and confirmed marked differences between the highly and less prolific isolates. Interestingly, a direct correlation between the invasion rates and tachyzoite yields, and the severity of the disease that was exhibited by infected pregnant mice in previous works could be established for the isolates in this study (Spearman's coefficient $>0.62, P<0.05$ ). The results of this study may help us to explain the differences in the pathogenicity that are displayed by different isolates.
\end{abstract}

\section{Introduction}

Neospora caninum is an obligate intracellular parasite that is phylogenetically related to Toxoplasma gondii and causes neuromuscular disease in dogs and abortion in cattle, although it can infect other host species $[1,2]$. Neosporosis is currently recognised as one of the main causes of infectious bovine abortion worldwide [1].

Previous studies have demonstrated that differences occur in the genetic and biological characteristics of $N$. caninum isolates. Thus, genetic diversity among N. caninum isolates has been detected using different polymorphic markers [3], including those that are based on microsatellite sequences, which were demonstrated to be the most suitable for typing $N$. caninum isolates [4-8]. Importantly, $N$. caninum isolates exhibit differences in

\footnotetext{
* Correspondence: jregidor@vet.ucm.es

'SALUVET, Animal Health Department, Complutense University of Madrid,

Ciudad Universitaria s/n, 28040 Madrid, Spain

Full list of author information is available at the end of the article
}

their capacity to produce pathology in cerebral mouse models [9-12], and in their efficacy to be transmitted from dams to offspring [13-16]. Genetic and biological intraspecific diversity of $N$. caninum isolates may influence their capacity to produce disease in the natural host, and the clinical presentation and epidemiology of neosporosis.

Very little information is known about the inherent factors of this parasite that contribute to its intra-specific pathogenicity, but the capacity to produce pathology has been associated with the behaviour of different $N$. caninum isolates in the host. The dissemination capacity, the parasite burdens that are reached in target tissues, the ability to avoid the immune response produced against the infection by the host and the rate of tachyzoite-bradyzoite conversion in the host may all contribute to the different levels of pathogenicity that are caused by different isolates [11-13,16,17]. Previous in vitro studies have reported that the growth $[18,19]$ and bradyzoite conversion rates $[14,20,21]$ are variable
C Biomed Central

(ㄷ) 2011 Regidor-Cerrillo et al; licensee BioMed Central Ltd. This is an Open Access article distributed under the terms of the Creative Commons Attribution License (http://creativecommons.org/licenses/by/2.0), which permits unrestricted use, distribution, and reproduction in any medium, provided the original work is properly cited. 
among different $N$. caninum isolates. Additionally, the low pathogenicity levels of the Nc-Spain $1 \mathrm{H}$ isolate in mice and cattle have been attributed to the low viability rate and tachyzoite yield of this isolate in cell cultures $[14,15]$. Therefore, similar to $T$. gondii, the inherent pathogenicity of different $N$. caninum isolates may be directly related to specific virulence traits, which include the migration capacity, the ability to cross barriers and the cell invasion and intracellular proliferation efficiencies [22-25].

In this work, we investigated the association between the in vitro phenotypes that were displayed by $N$. caninum isolates and their pathogenicity. Specifically, we examined the invasion efficiencies and the intracellular proliferation kinetics of eleven $N$. caninum isolates, including the naturally attenuated NcSpain-1 H isolate and the highly pathogenic Nc-Liverpool isolate, which showed profound differences in their vertical transmission characteristics and their capacities to induce pathology in pregnant cattle $[14,26]$.

\section{Materials and methods}

Cell cultures, parasites and preparation of $N$. caninum isolates for in vitro assays

The $N$. caninum isolates that were used in this study are shown in Table 1. The Spanish N. caninum isolates and the Nc-Liverpool (Nc-Liv) isolate were routinely maintained in a monolayer culture of the MARC-145 monkey kidney cell line after reactivation from cryovials, as described previously [5]. The Nc-Liv isolate was previously passaged in a mouse and re-isolated in MARC-145 cell cultures as described previously [16], to minimise the occurrence of potential alterations in its biological characteristics due to prolonged cell culture maintenance, as has been previously reported [27]. The $N$. caninum isolates that were used in these in vitro assays were subjected to a limited number of culture passages (Table 1).

The tachyzoites that were used in the in vitro assays were recovered from 3.5-day growth cultures, when the majority of the parasites were still intracellular (at least $80 \%$ of the parasite vacuoles were undisrupted in the cell monolayer), and purified using PD-10 (Sephadex G-25) columns (GE-Healthcare, Buckinghamshire, UK) prior to cell monolayer inoculations [28]. The tachyzoite inoculation dose was previously optimised for the maintenance of each isolate to estimate the recovery of tachyzoites from infected cultures under optimal conditions (actively replicating) at 3.5 days post-inoculation (pi). Infected cell cultures were scraped with a plastic cell scraper, harvested by centrifugation at $1350 \mathrm{~g}$ for $10 \mathrm{~min}$ and suspended in Dulbecco Minimum Essential Medium (DMEM) supplemented with a $2 \%$ antibioticantimycotic solution (Gibco BRL, Paisley, UK), $10 \mathrm{mM}$

Table 1 Neospora caninum isolates included in the in vitro assays

\begin{tabular}{|c|c|c|c|c|c|c|}
\hline Isolate* & Host origin** & $\begin{array}{c}\text { Geographical } \\
\text { origin }^{\&}\end{array}$ & $\begin{array}{l}\text { Passages } \\
\text { number }\end{array}$ & $\begin{array}{c}\text { Neonatal } \\
\text { morbidity }(\%)^{\#}\end{array}$ & $\begin{array}{c}\text { Neonatal } \\
\text { mortality }(\%)^{\#}\end{array}$ & $\begin{array}{c}\text { Vertical } \\
\text { transmission } \\
\text { rate }(\%)^{\#}\end{array}$ \\
\hline Nc-Spain $1 \mathrm{H}^{a}$ & 2-day-old healthy calf & Madrid & $12-18$ & $\mathrm{O}^{\mathrm{L}}$ & $5^{L}$ & $5^{\mathrm{L}}$ \\
\hline Nc-Spain 2H & 2-day-old healthy calf & Zaragoza & $7-13$ & $46.1^{\mathrm{L}}$ & $20.4^{L}$ & $61.3^{L}$ \\
\hline Nc-Spain $3 H^{b}$ & 52-day-old healthy calf & Navarra ${ }^{1}$ & $19-25$ & $10.6^{\mathrm{L}}$ & $7.7^{L}$ & $89^{H}$ \\
\hline Nc-Spain $4 \mathrm{H}^{b}$ & 22-day-old healthy calf & Navarra ${ }^{1}$ & $12-18$ & $100^{\mathrm{H}}$ & $100^{\mathrm{H}}$ & $97.3^{\mathrm{H}}$ \\
\hline Nc-Spain 5H & 14-day-old healthy calf & León & $12-18$ & $98.6^{\mathrm{H}}$ & $96^{\mathrm{H}}$ & $100^{\mathrm{H}}$ \\
\hline Nc-Spain 6 & 30-day-old healthy calf & País Vasco & $20-26$ & $34.5^{\mathrm{L}}$ & $29.8^{L}$ & $57.6^{\mathrm{L}}$ \\
\hline Nc-Spain 7 & 57-day-old healthy calf & Navarra ${ }^{2}$ & $17-23$ & $98.3^{\mathrm{H}}$ & $95^{\mathrm{H}}$ & $79.1^{L}$ \\
\hline Nc-Spain 8 & 2-day-old healthy calf & Navarra ${ }^{1}$ & $8-14$ & $4.7^{\mathrm{L}}$ & $1.1^{\mathrm{L}}$ & $56.4^{\mathrm{L}}$ \\
\hline Nc-Spain 9 & 7-day-old healthy calf & Navarra $^{2}$ & $9-15$ & $39^{L}$ & $32.5^{\mathrm{L}}$ & $52.6^{\mathrm{L}}$ \\
\hline Nc-Spain $10^{a}$ & 2-day-old affected calf? & Madrid & $21-27$ & $25.5^{\mathrm{L}}$ & $17.9^{L}$ & $65.5^{\mathrm{L}}$ \\
\hline Nc-Liverpool & 4-week-old affected dog & UK & 12R-19R@ & $100^{\mathrm{H}}$ & $100^{\mathrm{H}}$ & $95.6^{\mathrm{H}}$ \\
\hline
\end{tabular}

Summary of name, genetic characterisation, host and geographical origin, passage number in cell culture, and their pathogenicity in a BALB/C pregnant mouse model determined in previous studies $[14,16]$

* Nc-Liv and Spanish isolates were genetically characterised by microsatellite analysis. Letters in superscript $\left({ }^{\mathrm{a}}\right)$ and $\left({ }^{\mathrm{b}}\right)$ indicate isolates with identical microsatellite profiles $[4,5,14]$

**All Spanish isolates were obtained from asymptomatic calves from different cattle. Nc-Spain 10 was isolated from an affected calf, but its clinical signs could not be attributed to Neospora infection [5,14]. Nc-Liv was isolated from a clinically affected dog [50].

${ }^{\&}$ The geographical origin of Spanish isolates is indicated by province. Calves from Navarra originated from two dairy herds. Numbers in superscript $\left({ }^{1}\right)$ and $\left({ }^{2}\right)$ identify the dairy herd. Nc-Liverpool was isolated in the United Kingdom.

${ }^{\S}$ The total number of cell culture passages of the $N$. caninum isolates included in these in vitro assays. $\left({ }^{@}\right)$ marks the total passages after re-isolation of Nc-Liv in cell culture from BALB/c nu/nu mice.

${ }^{\#}$ The percentages of neonatal morbidity and neonatal mortality and vertical transmission rates were determined in previous studies using a pregnant BALB/C mouse model $[14,16] .{ }^{\mathrm{L}, \mathrm{H}}$ Isolates were categorised into lowly/moderately pathogenic $\left({ }^{\mathrm{L}}\right)$ or highly pathogenic $\left({ }^{\mathrm{H}}\right)$ groups according to the significant differences found in neonatal morbidity and mortality. Identical superscript letters denote highly $\left(^{\mathrm{H}}\right)$ and lowly/moderately transmissible $\left({ }^{\mathrm{L}}\right)$ isolates. 
HEPES and 2\% heat-inactivated foetal bovine serum (FBS). The FBS employed in all in vitro assays was from the same production batch. Disrupted cell cultures were passed through 25 gauge needles, and tachyzoites were purified with PD-10 columns that had been previously equilibrated with the medium mentioned above. Tachyzoites were eluted from the columns with $5 \mathrm{~mL}$ of medium, and the number of tachyzoites was determined by trypan blue exclusion followed by counting in a Neubauer chamber. Tachyzoites were then resuspended at the required doses $\left(2 \times 10^{5}\right.$ tachyzoites $\left./ \mathrm{mL}\right)$. Tachyzoite purification was performed at $4{ }^{\circ} \mathrm{C}$, and MARC-145 monolayers were inoculated within one hour of tachyzoite collection from flasks.

\section{In vitro invasion assays}

Host cell invasion was measured using a double (red/ green) immunostaining probe that was described previously [28] and a laser scanning-cytometer-based assay that was previously described for T. gondii [29], with several modifications. All of the isolates were assayed in triplicate, and all of the assays were performed in three independent experiments. The Nc-Liv isolate was included as a control in each batch of experiments. Additionally, MARC-145 monolayers that were not inoculated were immunostained and included as negative controls in each assay.

\section{Double immunofluorescence staining}

Purified parasites $\left(2 \times 10^{5}\right.$ tachyzoites $)$ were added onto MARC-145 monolayers that had grown to confluence on circular (13 mm diameter) glass coverslips and incubated at $37^{\circ} \mathrm{C}$ in a $5 \% \mathrm{CO}_{2}$ humidified incubator. At specific time periods ( $2 \mathrm{~h}, 4 \mathrm{~h}$ and $6 \mathrm{~h}$ pi), the coverslips were washed three times with $1 \mathrm{~mL}$ of phosphate buffered saline (PBS), fixed for $15 \mathrm{~min}$ in a 3\% formaldehyde $/ 0.05 \%$ glutaraldehyde solution and blocked with $3 \%$ bovine serum albumin (BSA) (Sigma-Aldrich, St. Louis, MO, USA) in PBS for 30 min. After blocking, the samples were labelled for $1 \mathrm{~h}$ with a 1:4000 dilution of a hyperimmune rabbit antiserum that was directed against $N$. caninum tachyzoites in PBS/0.3\% BSA, washed three times with PBS and then labelled for $1 \mathrm{~h}$ with a 1:100 dilution of a secondary goat anti-rabbit IgG that was conjugated to PE-Cy5.5 (red, Invitrogen, Carlsbad, CA, USA). After washing, the samples were permeabilised with $0.25 \%$ Triton X-100 and blocked with $\mathrm{PBS} / 3 \%$ BSA for $30 \mathrm{~min}$. Parasites were then labelled with the rabbit anti-tachyzoite serum as described above, washed, and labelled with a 1:1000 dilution of a secondary goat anti-rabbit IgG conjugated to Alexa Fluor 488 (green, Molecular Probes, Eugene, OR, USA). Finally, the coverslips were washed, mounted on slides embedded with a $40 \%$ glycerol $/ 2.5 \%$ 1,4-diazabicyclo[2.2.2] octane (Sigma-Aldrich) solution in PBS and analysed using a laser scanning cytometer. Polyclonal rabbit anti- $N$. caninum antiserum was raised in female New Zealand White rabbits (Harland Interfauna S.A., Barcelona, Spain) as described [30].

\section{Laser scanning cytometry}

The coverslips were analysed on a CompuCyte laser scanning cytometer LSC (CompuCyte, Cambridge, MA, USA) equipped with a BX50 upright fluorescence microscope (Olympus America, Melville, NY, USA). A 60.8 $\mathrm{mm}^{2}$ (4.4 mm radius) circular area was scanned with a $20 \times$ objective, an argon ion excitation laser $(488 \mathrm{~nm})$, and two detection filters (530/30 (green) and 650 LP (red)). Data were acquired and analysed using Wincyte 3.4 software (CompuCyte).

\section{Invasion rate determination}

The invasion rate (IR) was determined to be the number of green events (extracellular and intracellular parasites) minus the number of red events (extracellular parasites) per scanned field at specific times $(2 \mathrm{~h}, 4 \mathrm{~h}$ and $6 \mathrm{~h}$ pi). Negative controls (the MARC-145 monolayer that was not inoculated) were included to eliminate potential fluorescent artefacts. No events were observed in the negative control samples.

\section{In vitro intracellular proliferation assays}

Proliferation kinetics were determined by quantifying the number of tachyzoites at specific times $(4 \mathrm{~h}, 8 \mathrm{~h}$, $20 \mathrm{~h}, 32 \mathrm{~h}, 44 \mathrm{~h}, 56 \mathrm{~h}$, and $68 \mathrm{~h}$ pi) by real-time PCR (qPCR). All of the isolates were assayed in triplicate, and all of the assays were performed in three independent experiments. The Nc-Liv isolate was included in each batch of experiments as mentioned above, and MARC145 monolayers that were not inoculated were used as negative controls for PCR analyses.

\section{Culture conditions}

MARC-145 cells were grown to confluency in 24-well tissue culture plates. Purified $N$. caninum parasites $(2 \times$ $10^{5}$ tachyzoites) were added to the monolayers at time 0 and incubated for $4 \mathrm{~h}$ at $37^{\circ} \mathrm{C}$ in $5 \% \mathrm{CO}_{2}$. Next, the non-invading parasites were removed by washing the monolayer three times with DMEM/ $2 \%$ heat-inactivated FBS/2\% antibiotic solution. The cultures were subsequently maintained at $37^{\circ} \mathrm{C}$ in $5 \% \mathrm{CO}_{2}$ for the time periods mentioned above. The samples were visualised by light microscopy to monitor parasite proliferation prior to their collection. Then, the media were removed and the cell cultures were recovered in $200 \mu \mathrm{L}$ of PBS, $180 \mu \mathrm{L}$ of lysis buffer and $20 \mu \mathrm{L}$ of proteinase $\mathrm{K}$ (Qiagen, Hilden, Germany). The samples were transferred to Eppendorf tubes and were frozen at $-80^{\circ} \mathrm{C}$ prior to DNA extraction.

\section{$D N A$ extraction and real-time $P C R$}

Genomic DNA was extracted from cellular samples using the BioSprint 96 workstation and the BioSprint 96 
DNA blood kit (Qiagen) according to the manufacturer's instructions. Genomic DNA was eluted in a final volume of $100 \mu \mathrm{L}$.

Quantification of N. caninum DNA was performed by real-time PCR targeting the Nc-5 region as described previously [31]. A total of $5 \mu \mathrm{L}$ (100 ng) DNA was used for the PCR amplifications. The number of $N$. caninum parasites was calculated by interpolating the corresponding $\mathrm{Ct}$ values (cycle threshold value, which represents the fractional cycle number reflecting a positive PCR result) on a standard curve that was generated in each real-time PCR run by assaying 10 -fold serial dilutions of parasite DNA, which was equivalent to $10^{-1}-10^{5}$ tachyzoites. All of the tachyzoite quantifications were assessed from average values obtained from duplicate determinations. DNA extracted from the uninfected MARC-145 monolayer was also included as a negative PCR control in each batch of reactions.

\section{Proliferation rate, doubling time and tachyzoite yield determinations}

The proliferation rate $(\mu)$ and doubling time $(\mathrm{Td})$ were assessed for each assay during the exponential multiplication period by applying non-linear regression analysis and an exponential growth equation using GraphPad Prism 5 Demo, v. 5.00 software (GraphPad, San Diego, CA, USA). The $\mu$ and $\mathrm{Td}$ for each isolate were defined as the average value obtained from all of the determinations that revealed a linear regression, $R^{2} \geq 0.95$.

The tachyzoite yield $\left(\mathrm{TY}_{56 \mathrm{~h}}\right)$ was defined as the average value of the number of tachyzoites quantified by qPCR at $56 \mathrm{~h}$ pi.

\section{Data statistics and correlation analysis}

Differences between IRs determined over successive time points for each isolate were compared using the $\mathrm{U}$ Mann-Whitney test ( $2 \mathrm{~h}$ versus $4 \mathrm{~h}, 2 \mathrm{~h}$ versus $6 \mathrm{~h}, 4 \mathrm{~h}$ versus 6 h). The Kruskal-Wallis test was employed for comparisons among the IRs shown for the different isolates within each time point $(2 \mathrm{~h}, 4 \mathrm{~h}$, and $6 \mathrm{~h}$ pi). When statistically significant differences were found with the Kruskal-Wallis test, a Dunn's multiple-comparison test was applied to examine all of the possible pairwise comparisons. A one-way ANOVA test, followed by the Tukey's multiple range tests, was employed to compare the Tds and $\mathrm{TY}_{56 \mathrm{~h}} \mathrm{~S}$ assessed for each isolate. Statistical analyses were carried out using a dataset composed of the values determined for each replicate obtained from the three independent experiments. The significance for these analyses was established at $P<0.05$.

The Spearman's rank correlation coefficient $(\rho)$ was applied to investigate the potential association between the in vitro parameters evaluated in this study $\left(\mathrm{IR}_{2 \mathrm{~h}}\right.$, $\mathrm{IR}_{4 \mathrm{~h}}, \mathrm{IR}_{6 \mathrm{~h}}, \mathrm{Td}, \mathrm{TY}_{56 \mathrm{~h}}$ ) and the neonatal morbidity, mortality and vertical transmission rates induced by these isolates in a well-established pregnant mouse model (Table 1) $[14,16]$.

Statistical and correlation analyses were performed, and graphics were generated using GraphPad Prism 5 Demo, v. 5.00 software (GraphPad).

\section{Results}

\section{Invasion rate comparisons}

The IRs (the median number of intracellular events) of almost all isolates significantly increased from $2 \mathrm{~h}$ to $4 \mathrm{~h}$ pi or from $2 \mathrm{~h}$ to $6 \mathrm{~h}$ pi $(P<0.05, U$ Mann-Whitney test), with the exception of the Nc-Spain 9 isolate. However, no significant differences were found between the IRs of most of the isolates at 4 and $6 \mathrm{~h}$ pi. The IRs were only observed to significantly increase from $4 \mathrm{~h}$ to $6 \mathrm{~h}$ pi for the Nc-Spain $1 \mathrm{H}$ and Nc-Spain 10 isolates.

Significant differences were also found among the IRs of different isolates at 2 and $4 \mathrm{~h}$ pi $(P<0.0001$, KruskalWallis test) (Figure $1 \mathrm{~A}$ and $\mathrm{B}$ ). At $2 \mathrm{~h}$ pi, the Nc-Spain $4 \mathrm{H}, \mathrm{Nc}$-Spain 8 and Nc-Liv isolates exhibited the highest IRs $\left(I_{2 h}\right)$ in comparison to the $I_{2 h} \mathrm{~S}$ of the NcSpain $3 \mathrm{H}$, Nc-Spain 6 and Nc-Spain 10 isolates, which displayed the lowest values (by Dunn's test). At $4 \mathrm{~h} \mathrm{pi}$, the Nc-Spain $4 \mathrm{H}$ and Nc-Liv isolates exhibited significantly higher IRs $\left(\mathrm{IR}_{4 \mathrm{~h}}\right)$ than the Nc-Spain $3 \mathrm{H}$ and NcSpain $1 \mathrm{H}$ isolates when they were analysed by the Dunn's test. Significant variations among the IRs of the isolates were also detected at $6 \mathrm{~h}$ pi $(P=0.046$, KruskalWallis test), although no differences were found in pairwise analyses between the IRs of the different isolates (Figure 1C).

\section{Proliferation kinetics, proliferation rate determination and doubling time comparisons}

The parasite proliferation kinetics of each $N$. caninum isolate was studied by plotting the numbers of tachyzoites, which were determined by $\mathrm{qPCR}$, against the specific collection time periods (Figure 2A). After being inoculated onto MARC-145 cell monolayers, tachyzoites did not multiply for a specific period of time, which is known as the lag phase. The lag phase of the different isolates varied between the time periods of $8 \mathrm{~h}$ (Nc-Spain 10), $20 \mathrm{~h}$ (Nc-Spain $4 \mathrm{H}$, Nc-Spain 5 H, Nc-Spain 7, Nc-Spain 6 and Nc-Liv), 32 h (Nc-Spain $1 \mathrm{H}, \mathrm{Nc}-$ Spain $3 \mathrm{H}$ and Nc-Spain 9) and 44 h (Nc-Spain $2 \mathrm{H}, \mathrm{Nc}-$ Spain 8) (Figure 2A). After the lag phase, an exponential proliferation phase was observed that persisted until $56 \mathrm{~h}$ pi for 3 of the 11 isolates (Nc-Spain $4 \mathrm{H}, \mathrm{Nc}$-Spain $5 \mathrm{H}$ and Nc-Spain 7 isolates) and until $68 \mathrm{~h}$ pi for the other 8 isolates (Figure 2B). Microscopic visualisation of the inoculated cultures prior to collection verified that some parasitophorous vacuoles with tachyzoite pairs were first observed for most of the isolates at $20 \mathrm{~h}$ pi. After $32 \mathrm{~h}$, the number of 

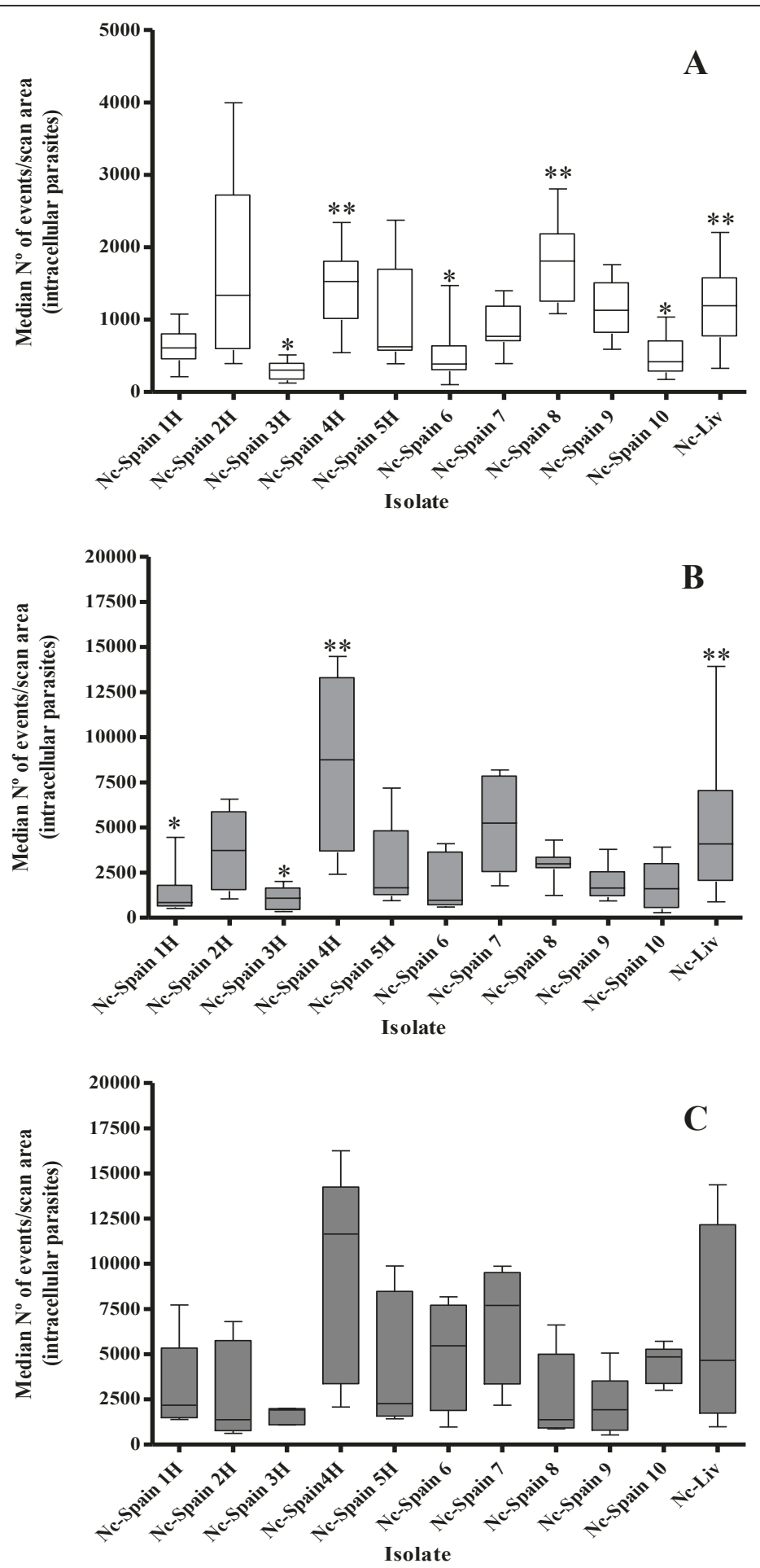

Figure 1 Box-plot graphs representing the maximum and minimum values, lower and upper quartiles and medians of invasion rate (IR) replicates from experiments performed in triplicate determined in vitro for each $\mathbf{N}$. caninum isolate. IRs at $2 \mathrm{~h} \mathrm{pi}$ (A). IRs at $4 \mathrm{~h}$ pi (B). IRs at $6 \mathrm{~h}$ pi (C). Error bars indicate the SD. $\left(^{* *}\right)$ marks the significantly higher IRs compared with all of those IRs that were significantly lower $\left.{ }^{*}\right)$ according to the Kruskal-Wallis test and the Dunn's multiple-comparison test. 
tachyzoites from the $N$. caninum isolates that were undergoing endodyogeny inside of parasite vacuoles increased with increasing time. Between 56 and $68 \mathrm{~h}$ pi, non-synchronous rupture of the host cells and egression of the tachyzoites were observed in the cell monolayers infected with 7 of the 11 isolates (Nc-Spain $4 \mathrm{H}$, NcSpain 5 H, Nc-Spain 6, Nc-Spain 7, Nc-Spain 9, NcSpain 10, and Nc-Liv).

The $\mu$ and the $\mathrm{Td}$ were determined for the exponential phase, excluding the lag and egression periods, for each

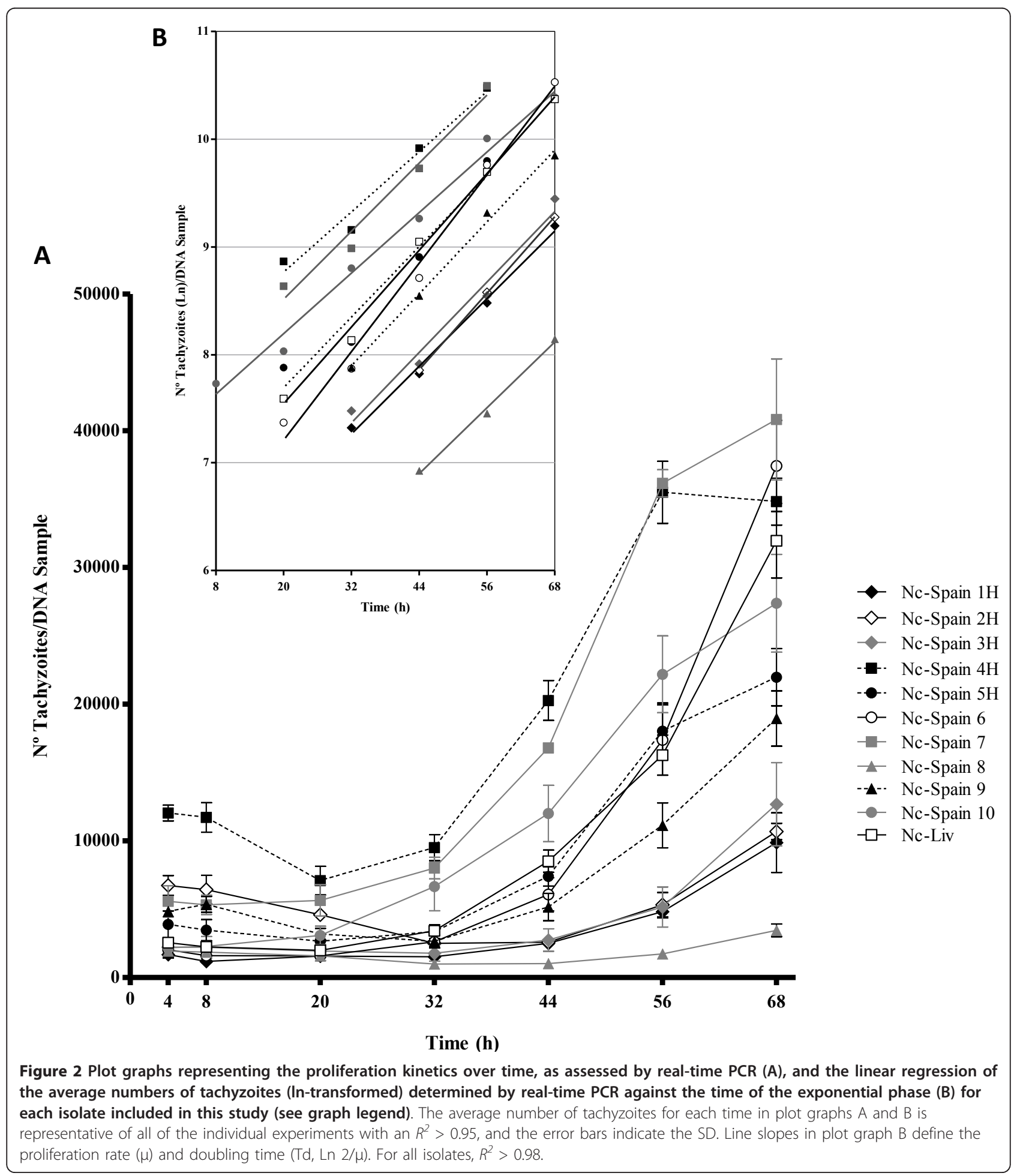


replicate performed for each isolate with an $R^{2}>0.95$. The average $\mathrm{Td}$ values for different isolates ranged from a minimum of $9.84 \pm 1.516 \mathrm{~h}$ (Nc-Spain 6) to a maximum of $14.15 \pm 2.364 \mathrm{~h}$ (Nc-Spain $4 \mathrm{H}$ ) (Figure 3). When the $\mathrm{Td}$ values assessed for different isolates were compared, significant differences were detected (Figure 3). The Td value of the Nc-Spain $4 \mathrm{H}$ isolate was significantly higher than the Td values of the Nc-Spain $5 \mathrm{H}$, Nc-Spain 6 and Nc-Liv isolates $(P=0.0016$ by 1 -way ANOVA, followed by Tukey's test).

\section{Evaluation of tachyzoite yield}

The $\mathrm{TY}_{56 \mathrm{~h}}$ was assessed to determine the number of tachyzoites produced during the same intracellular period after invasion, but prior to complete tachyzoite egression from cell monolayers. The $\mathrm{TY}_{56} \mathrm{~h}$ values were significantly different between isolates $(P<$ 0.0001 by 1-way ANOVA, followed by Tukey's test) and varied from 1731 (Nc-Spain 8) to 36170 tachyzoites (Nc-Spain 7) (Figure 4). At $56 \mathrm{~h} \mathrm{pi}$, the isolates that were already undergoing exponential proliferation from $20 \mathrm{~h}$ pi (Nc-Spain $4 \mathrm{H}$, Nc-Spain $5 \mathrm{H}$, Nc-Spain 6, Nc-Spain 7, Nc-Spain 10 and Nc-Liv) had significantly higher $\mathrm{TY}_{56} \mathrm{~h}$ values than the other four isolates (Nc-Spain $1 \mathrm{H}, \mathrm{Nc}$-Spain $2 \mathrm{H}, \mathrm{Nc}$-Spain $3 \mathrm{H}$, and NcSpain 8 ), which began to exponentially proliferate after $20 \mathrm{~h}$ pi (Figure 4).

\section{Correlation analysis}

Previous studies using a well-established pregnant $\mathrm{BALB} / \mathrm{c}$ mouse model demonstrated that extensive

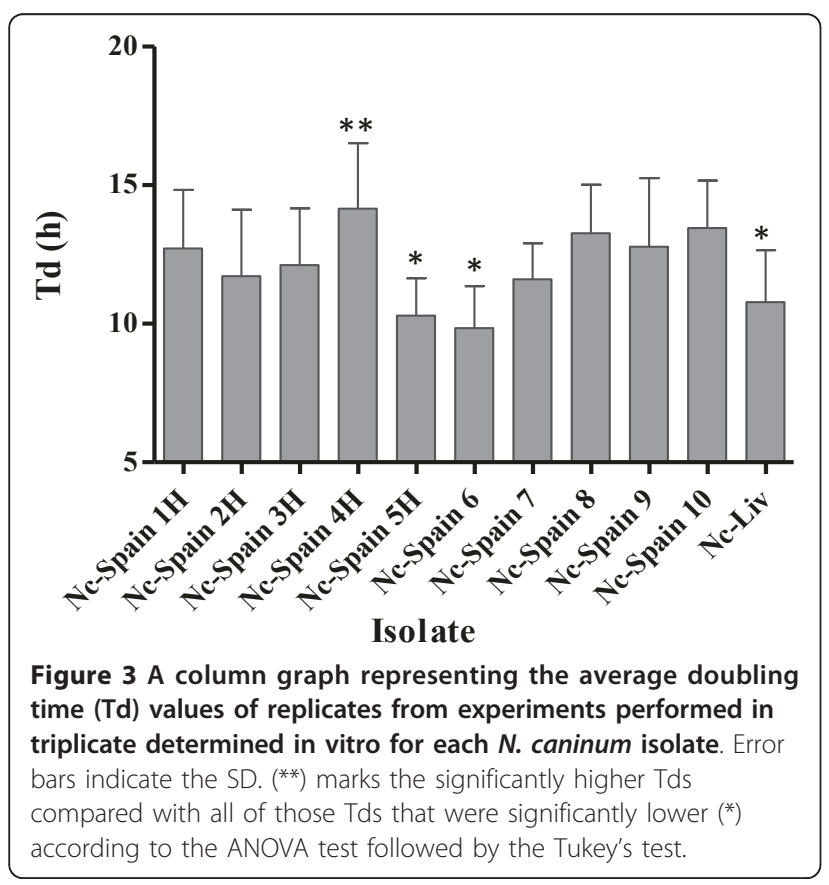

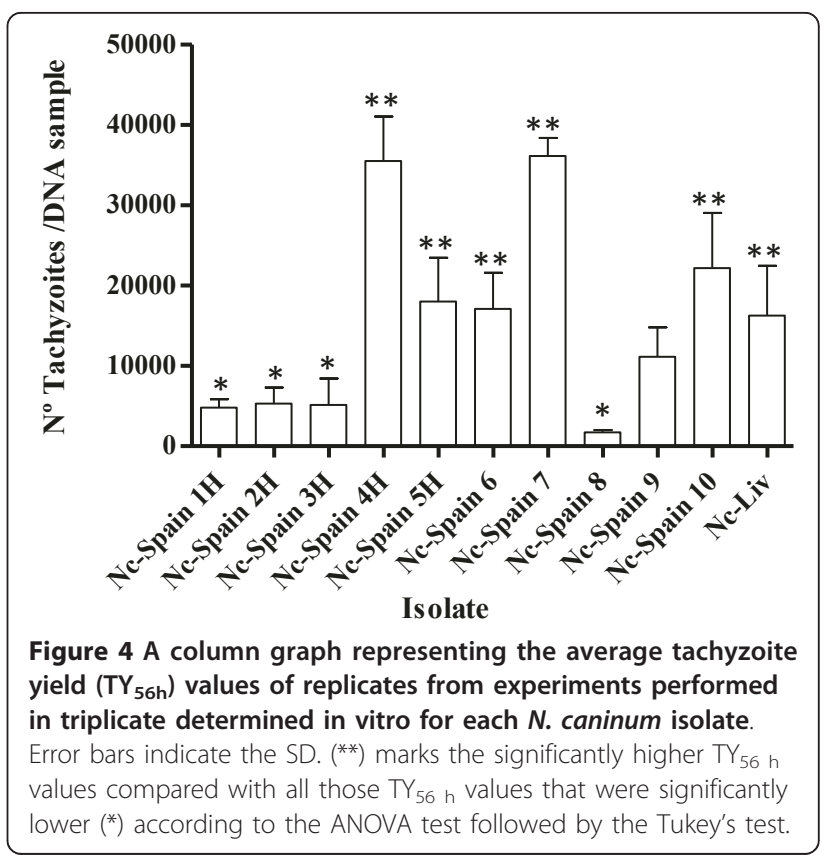

variability exists in the pathogenicity and transmissibility of the $N$. caninum isolates included in this study $[14,16]$. Wide ranges in the morbidity, mortality and vertical transmission rates were observed (Table 1), suggesting a relevant role of the implicated isolate in the outcome of infection in pregnant mice. Because the in vitro IRs, $\mathrm{Td}$ and $\mathrm{TY}_{56} \mathrm{~h}$ values also varied significantly within this population of isolates, Spearman correlation analyses were applied to determine whether a potential association existed between the in vitro characteristics of isolates and their ability to be vertically transmitted and produce disease in mice. No correlations could be discerned between the $T d$ or $I_{2} h$ values and vertical transmission, neonatal morbidity or neonatal mortality rates. Additionally, no correlation could be established between the vertical transmission rates and the $\mathrm{IR}_{4} \mathrm{~h}, \mathrm{IR}_{6 \mathrm{~h}}$ or $\mathrm{TY}_{56 \mathrm{~h}}$ values. However, a significant correlation was found between the $\mathrm{IR}_{4} \mathrm{~h}$, $\mathrm{IR}_{6} \mathrm{~h}$ and $\mathrm{TY}_{56} \mathrm{~h}$ values and neonatal morbidity and mortality rates based on the Spearman's rho coefficient (Table 2).

\section{Discussion}

The apicomplexan parasite $N$. caninum is an obligate intracellular parasite. The processes of parasite invasion, adaptation to new intra-cytoplasmatic conditions, intracellular proliferation, and egress from host cells constitute successive steps involved in the lytic cycle of $N$. caninum and other apicomplexa [32-34]. These processes are required for the maintenance and multiplication of the parasite in vitro and for parasite survival and propagation in the course of animal infection in vivo. As 


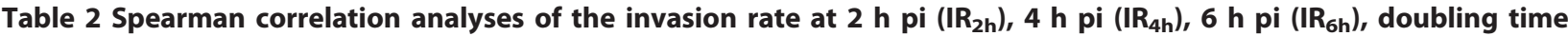
(Td), and the tachyzoite yield at $56 \mathrm{~h}$ pi $\left(\mathrm{TY}_{56 \mathrm{~h}}\right)$ that were determined in vitro for each isolate in this study

\begin{tabular}{|c|c|c|c|c|c|c|c|c|c|c|}
\hline & \multicolumn{2}{|c|}{$\mathbf{I R}_{2 \mathrm{~h}}$} & \multicolumn{2}{|c|}{$\mathbf{I R}_{\mathbf{4 h}}$} & \multicolumn{2}{|c|}{$\mathbf{I R}_{6 \mathrm{~h}}$} & \multicolumn{2}{|c|}{$\mathrm{Td}$} & \multicolumn{2}{|c|}{$\mathrm{TY}_{56 \mathrm{~h}}$} \\
\hline & $\rho^{*}$ & $P^{\#}$ & $\rho$ & $P$ & $\rho$ & $P$ & $\rho$ & $P$ & $\rho$ & $P$ \\
\hline Neonatal morbidity & N.C. & - & 0.7107 & 0.018 & 0.7016 & 0.020 & N.C. & - & 0.7614 & 0.0065 \\
\hline Neonatal mortality & N.C. & - & 0.6287 & 0.044 & 0.7198 & 0.016 & N.C. & - & 0.7198 & 0.016 \\
\hline Vertical transmission rate & N.C. & - & N.C. & - & N.C. & - & N.C. & - & N.C. & - \\
\hline
\end{tabular}

* Spearman rho coefficient.

\# $P$ value (two-tailed).

N.C. No correlation.

a result of a primo-infection or the reactivation of a Neospora infection in a chronically infected animal, tachyzoites rapidly disseminate throughout the body of the host, invade cells of different organs and cause cell death. Cell death results in the release of parasites, which develop new lytic replication cycles, thus allowing the infection to spread and cause disease [1]. Therefore, the processes involved in parasite invasion and intracellular proliferation are crucially important for understanding the pathogenesis of disease and for the development of protective vaccines and effective drug therapies. Recently, different studies have been performed to understand the precise mechanisms involved in the processes of the $N$. caninum lytic cycle, which includes parasite invasion [28,35,36] and egress [37]. However, intraspecific differences related to the efficiency of the lytic cycle processes, such as invasion and proliferation, and their association with isolate pathogenicity in vivo have been poorly investigated. The most detailed study in this regard was performed by Schock et al. [19], which revealed that differences occurred in the growth rates of six $N$. caninum isolates, although their potential correlation with virulence was not examined. Moreover, the isolates in this previous study were maintained by an undetermined number of culture passages, which could modify the original growth rate and pathogenicity of the isolates [27]. Attenuation of virulence, accompanied by faster multiplication in vitro has been previously demonstrated in $N$. caninum and $T$. gondii parasites maintained for extended periods in cell cultures, which may have been due to adaptation of the isolates to cell cultivation $[27,38]$. In this study, we comparatively examined the in vitro invasion efficiencies and proliferation kinetics of the active tachyzoite stage of eleven different $N$. caninum isolates, which were maintained with limited passages in cell cultures from their original isolation $[5,14]$.

The IRs determined in this study demonstrated that the tachyzoites from most of the $N$. caninum isolates penetrated cell monolayers 2 to $4 \mathrm{~h}$ pi. In previous studies, tachyzoites from the Nc-1 $N$. caninum isolate penetrated bovine aorta endothelial cell cultures 45-60 min after inoculation [28]. After the initial penetrations, an insignificant increase in the number of invading tachyzoites was detected from 4 to $6 \mathrm{~h}$ pi. This slight increase was likely due to the loose invasion capacity of the remaining tachyzoites that had not invaded that monolayer at $4 \mathrm{~h} \mathrm{pi}$ $[28,35]$. These results were similar to the results reported by Hemphill et al. [28], who observed that maintaining $\mathrm{Nc}-1$ tachyzoites extracellularly at $37^{\circ} \mathrm{C}$ for time periods longer than 4-6 h resulted in decreased infectivity of the parasite. The observed differences in the invasion time periods of $N$. caninum tachyzoites may also have been influenced by the experimental conditions and the host cell types used in each experiment. N. caninum can be maintained in vitro in a wide variety of well-established cell cultures, and thus, this parasite can invade a wide range of cell cultures, although $N$. caninum tachyzoites from different isolates may have different affinities for specific cell types. Based on this theory, the failure to isolate parasites in CV-1 and M617 cells from a clinically affected $\mathrm{KO}$ mouse can be attributed to the limited invasion and growth characteristics of the specific isolate in these cell lines [39]. This theory may also explain the natural host range and the tissue tropism displayed by $N$. caninum during infection. Moreover, in previous studies, substantial differences were observed in the cell invasion processes of the closely related $N$. caninum and $T$. gondii parasites, which could explain their dissimilar host preferences [35]. However, different $N$. caninum isolates, including those that were assayed in this study, could all be adapted to the MARC-145 cell line through a limited number of cell passages $[5,14,18]$. Therefore, the significant differences in the invasion efficiencies observed in this study could be attributed to the biological diversity of these $N$. caninum isolates. Throughout the experiments, the IRs determined for the Nc-Spain $4 \mathrm{H}$ and NcLiv isolates were significantly higher than the IR of the $\mathrm{Nc}$-Spain $3 \mathrm{H}$ isolate. Furthermore, the IRs determined for the Nc-Spain $4 \mathrm{H}$ and Nc-Liv isolates were significantly higher than the IR of the $\mathrm{Nc}$-Spain $1 \mathrm{H}$ isolate at 4 h pi (Figure 1).

The intracellular proliferation kinetics also varied between the isolates that were analysed. Significant 
differences in the lag period, which ranged from 8 to 44 h pi, were observed between the isolates. Additionally, after the exponential proliferation period, the egress period, which occurred 56 to $68 \mathrm{~h}$ pi, was only detected in some of the isolates. Furthermore, we did not microscopically visualise parasitophorous vacuoles containing two or more tachyzoites until $20 \mathrm{~h} \mathrm{pi}$, and the cellular rupture releasing the tachyzoites was observed for some of the isolates from $56 \mathrm{~h}$ pi. The exponential proliferation period is delimited by the lag phase and the tachyzoite egress phase for each isolate.

The Td values, which signify the $\mu$, also varied from approximately 10 to $14 \mathrm{~h}$, and significant differences in the values were detected between the isolates. Our results were similar to the results previously obtained for the Nc-1 isolate, which displayed a lag period of 10-12 $\mathrm{h}$ and a Td of 14-15 h using human foreskin fibroblasts [40]. However, we must consider, as we did for the IRs, that the proliferation kinetics may have been influenced by the host cell lines used in these assays [39]. In fact, previous studies on T. gondii have demonstrated that differences in tachyzoite multiplication occur based on the cell lines used as hosts [41].

Variations in the IR, Td (proliferation rate) and the exponential proliferation period will determine the number of tachyzoite division cycles reached and the tachyzoite yield attained in vitro and in vivo. Significant differences in the $\mathrm{TY}_{56} \mathrm{~h}$ values were apparent between the isolates based on comparative analysis, and the isolates clearly grouped into two populations: "highly prolific" and "less prolific" (Figure 4). Interestingly, the severity of histopathological lesions and clinical signs have been directly related to the parasite burdens in the brains of experimentally infected mice $[11,12,42-45]$ and to the spread of the parasite in foetal and placental tissues from infected pregnant cattle $[1,15,26,32,46]$. Furthermore, an association between the severity of histological lesions and parasite burdens was established in studies performed in bovine foetuses that were naturally aborted during different periods of pregnancy [47]. Therefore, the high dissemination rate, the ability to cross biological barriers (blood-brain barrier and placenta) and the enhanced invasion and proliferation rates of different N. caninum isolates may contribute to host tissue damage and to the severity of clinical signs in vivo. In support of this hypothesis, we observed that the isolates with the highest IRs (Nc-Spain $4 \mathrm{H}$ and Nc-Liv) caused the highest morbidity in dams and the highest morbidity and mortality in neonates $(100 \%$ succumbed to infection), while the isolates with the lowest IRs (Nc-Spain $1 \mathrm{H}$ and $\mathrm{Nc}$-Spain $3 \mathrm{H}$ ) induced lower neonatal mortality in a pregnant mouse model $[14,16]$. Furthermore, the "highly prolific" and "less prolific" isolate populations contained isolates that displayed the highest ( $\mathrm{Nc}$-Spain $5 \mathrm{H}$ and $\mathrm{Nc}$-Spain 7) and lowest ( $\mathrm{Nc}$ Spain $2 \mathrm{H}$ and Nc-Spain $3 \mathrm{H}$ ) parasite burdens and the levels of histopathological lesions in the brain during the chronic phase of infection in a cerebral mouse model, respectively [12]. Interestingly, this system of ordering grouped the isolates that had the highest and lowest capacities to produce disease in the pregnant mouse model together (Table 1) $[14,16]$. Based on these observations, the association between the in vitro IRs and $\mathrm{TY}_{56} \mathrm{~h}$ values for these isolates and the neonatal morbidity, mortality and vertical transmission rates produced by these isolates in mice was investigated through a correlation analysis. A direct correlation between the $\mathrm{IR}_{4 \mathrm{~h}}$ and $\mathrm{IR}_{6} \mathrm{~h}$ values when invasion was completed, as well as the $\mathrm{TY}_{56} \mathrm{~h}$ value and their pathogenicity in mice was established, suggesting that the in vitro invasion and proliferation rate traits are related to the in vivo virulence of the $N$. caninum isolates, at least in the pregnant BALB/c mouse model. Moreover, the Nc-Spain $1 \mathrm{H}$ isolate (a "less prolific" and less invasive isolate in this study) had a limited ability to induce foetal death in a pregnant bovine model [15]. High growth rates due to a higher reinvasion capacity, but not due to significant variations between isolate-specific Tds, have also been recognised as a virulence trait in T. gondii [25], though pathogenesis in toxoplasmosis has mainly been found to be related to the inflammatory immune response against infection by specific $T$. gondii types $[22,48]$. However, virulence factors, such as the ROP18 and ROP16 rhoptry proteins, have recently been identified in T. gondii, and the ability of ROP18 to increase the intracellular proliferation of this parasite has been specifically suggested to cause enhanced virulence of the parasite $[23,25,49]$. Because the outcome of $N$. caninum infection is affected by a combination of host, parasite, and external factors, these factors need to be considered collectively when establishing direct associations between the in vitro and in vivo behaviour of $N$. caninum isolates. Various parasite factors, which include the efficacy of disseminating and crossing host barriers, may also be different between $N$. caninum isolates, as described for $T$. gondii isolate types I, II and III $[22,23]$. Therefore, differences may also exist between $N$. caninum isolates in the number of parasites that are able to spread throughout the host and colonise target organs (brain and placenta) and, consequently, the tachyzoite yield reached in the target tissues, the outcome of an infection and the transmission of the parasite to foetuses in pregnant animals. These differences may explain the lack of a correlation found between the IRs and $\mathrm{TY}_{56} \mathrm{~h}$ values with vertical transmission rates. 
Interestingly, the genetically identical Nc-Spain 1 $\mathrm{Nc}$-Spain 10 and Nc-Spain $3 \mathrm{H}$ - Nc-Spain $4 \mathrm{H}$ isolates displayed significant differences in their in vitro behaviour, as well as in their pathogenicity in mice $[14,16]$. Both pairs of isolates were obtained from the same dairy herd, but from different calves, and therefore, they could be considered as different isolates that may include genetic variations in other loci that were not examined.

In summary, this study showed that there is intraspecific diversity in the invasion rate and proliferation kinetics of different $N$. caninum isolates. More interestingly, the correlation found between the in vitro characteristics of the isolates with their in vivo pathogenicity in pregnant mice and their offspring confirms that invasion and proliferation rates are virulence traits in N. caninum. Within apicomplexan parasites, host cell invasion and intracellular proliferation are tightly regulated processes that involve the sequential secretion of components from specialised organelles (micronemes, rhoptries and dense granules). A large number of these secreted elements and their interactions have already been identified in T. gondii [24]. Some of these elements, such as the ROP18 and ROP16 proteins, are virulence factors in $T$. gondii $[23,25,49]$. In contrast to $T$. gondii, the role of orthologous microneme, roptry and dense granule proteins in $N$. caninum is still unclear. In addition, cell culturebased approaches have demonstrated significant differences between $T$. gondii and $N$. caninum species $[32,35]$. Further studies are necessary to identify the molecular mechanisms within N. caninum that are directly involved in mediating the differences observed between various isolates.

\section{Acknowledgements}

This work was supported by the INIA project RTA04-047-C2. We thank Diana Williams (Liverpool School of Tropical Medicine, Liverpool, UK), who kindly provided us with the Nc-Liv isolate. We also thank the Flow Cytometry and Confocal Microscopy Unit of the Complutense University of Madrid for their technical support and Ricardo García de la Mata from the Complutense University of Madrid for statistical analyses.

\section{Author details}

'SALUVET, Animal Health Department, Complutense University of Madrid, Ciudad Universitaria s/n, 28040 Madrid, Spain. ${ }^{2}$ NEIKER-Tecnalia, Berreaga 1, Derio, 48160 Vizcaya, Spain.

\footnotetext{
Authors' contributions

JRC carried out in vitro assays, conceived the study, participated in its design, and drafted the manuscript. MGB participated in invasion assays, in its design and helped to draft the manuscript. IS performed invasion and proliferation assays. GA participated in the design of the study and coordination. GAG participated in proliferation assays and performed the statistical analysis. IP carried out real-time PCR determinations. LMO also conceived the study, participated in the design of the study and coordination, and helped to draft the manuscript. All authors read and approved the final manuscript.
}

\section{Competing interests}

The authors declare that they have no competing interests.

Received: 30 June 2010 Accepted: 23 February 2011

Published: 23 February 2011

\section{References}

1. Dubey JP, Buxton D, Wouda W: Pathogenesis of bovine neosporosis. J Comp Pathol 2006, 134:267-289.

2. Dubey JP, Schares G, Ortega-Mora LM: Epidemiology and control of neosporosis and Neospora caninum. Clin Microbiol Rev 2007, 20:323-367.

3. Beck HP, Blake D, Darde ML, Felger I, Pedraza-Diaz S, Regidor-Cerrillo J, Gomez-Bautista M, Ortega-Mora LM, Putignani L, Shiels B, Tait A, Weir W: Molecular approaches to diversity of populations of apicomplexan parasites. Int J Parasitol 2009, 39:175-189.

4. Regidor-Cerrillo J, Pedraza-Diaz S, Gomez-Bautista M, Ortega-Mora LM: Multilocus microsatellite analysis reveals extensive genetic diversity in Neospora caninum. J Parasitol 2006, 92:517-524.

5. Regidor-Cerrillo J, Gomez-Bautista M, Pereira-Bueno J, Aduriz G, Navarro-Lozano V, Risco-Castillo V, Fernandez-Garcia A, PedrazaDiaz S, Ortega-Mora LM: Isolation and genetic characterization of Neospora caninum from asymptomatic calves in Spain. Parasitology 2008, 135:1651-1659.

6. Al-Qassab S, Reichel MP, Ivens A, Ellis JT: Genetic diversity amongst isolates of Neospora caninum, and the development of a multiplex assay for the detection of distinct strains. Mol Cell Probes 2009, 23:132-139.

7. Basso W, Schares S, Barwald A, Herrmann DC, Conraths FJ, Pantchev N, Vrhovec MG, Schares G: Molecular comparison of Neospora caninum oocyst isolates from naturally infected dogs with cell culture-derived tachyzoites of the same isolates using nested polymerase chain reaction to amplify microsatellite markers. Vet Parasitol 2009, 160:43-50.

8. Pedraza-Diaz S, Marugan-Hernandez V, Collantes-Fernandez E, RegidorCerrillo J, Rojo-Montejo S, Gomez-Bautista M, Ortega-Mora LM: Microsatellite markers for the molecular characterization of Neospora caninum: application to clinical samples. Vet Parasitol 2009, 166:38-46.

9. Lindsay DS, Lenz SD, Cole RA, Dubey JP, Blagburn BL: Mouse model for central nervous system Neospora caninum infections. J Parasitol 1995, 81:313-315.

10. Atkinson R, Harper PA, Ryce C, Morrison DA, Ellis JT: Comparison of the biological characteristics of two isolates of Neospora caninum. Parasitology 1999, 118:363-370.

11. Collantes-Fernandez E, Lopez-Perez I, Alvarez-Garcia G, Ortega-Mora LM: Temporal distribution and parasite load kinetics in blood and tissues during Neospora caninum infection in mice. Infect Immun 2006, 74:2491-2494.

12. Pereira Garcia-Melo D, Regidor-Cerrillo J, Collantes-Fernandez E, AguadoMartinez A, Del Pozo I, Minguijon E, Gomez-Bautista M, Aduriz G, OrtegaMora LM: Pathogenic characterization in mice of Neospora caninum isolates obtained from asymptomatic calves. Parasitology 2010, 137:1057-1068.

13. Quinn HE, Miller CM, Ryce C, Windsor PA, Ellis JT: Characterization of an outbred pregnant mouse model of Neospora caninum infection. J Parasitol 2002, 88:691-696.

14. Rojo-Montejo S, Collantes-Fernandez E, Regidor-Cerrillo J, Alvarez-Garcia G, Marugan-Hernandez V, Pedraza-Diaz S, Blanco-Murcia J, Prenafeta A, OrtegaMora LM: Isolation and characterization of a bovine isolate of Neospora caninum with low virulence. Vet Parasitol 2009, 159:7-16.

15. Rojo-Montejo S, Collantes-Fernandez E, Blanco-Murcia J, Rodriguez-Bertos A, Risco-Castillo V, Ortega-Mora LM: Experimental infection with a low virulence isolate of Neospora caninum at 70 days gestation in cattle did not result in foetopathy. Vet Res 2009, 40:49.

16. Regidor-Cerrillo J, Gomez-Bautista M, Del Pozo I, Jimenez-Ruiz E, Aduriz G, Ortega-Mora LM: Influence of Neospora caninum intra-specific variability in the outcome of infection in a pregnant BALB/c mouse model. Vet Res 2010, 41:52.

17. Quinn HE, Miller CM, Ellis JT: The cell-mediated immune response to Neospora caninum during pregnancy in the mouse is associated with a bias towards production of interleukin-4. Int J Parasitol 2004, 34:723-732.

18. Perez-Zaballos FJ, Ortega-Mora LM, Alvarez-Garcia G, Collantes-Fernandez E, Navarro-Lozano V, Garcia-Villada L, Costas E: Adaptation of Neospora 
caninum isolates to cell-culture changes: an argument in favor of its clonal population structure. J Parasitol 2005, 91:507-510.

19. Schock A, Innes EA, Yamane I, Latham SM, Wastling JM: Genetic and biological diversity among isolates of Neospora caninum. Parasitology 2001, 123:13-23.

20. Vonlaufen N, Muller N, Keller N, Naguleswaran A, Bohne W, McAllister MM Bjorkman C, Muller E, Caldelari R, Hemphill A: Exogenous nitric oxide triggers Neospora caninum tachyzoite-to-bradyzoite stage conversion in murine epidermal keratinocyte cell cultures. Int J Parasitol 2002, 32:1253-1265.

21. Weiss $L M, M a$ YF, Halonen $S, M c A l l i s t e r ~ M M$, Zhang YW: The in vitro development of Neospora caninum bradyzoites. Int J Parasitol 1999, 29:1713-1723.

22. Saeij JP, Boyle JP, Boothroyd JC: Differences among the three major strains of Toxoplasma gondii and their specific interactions with the infected host. Trends Parasitol 2005, 21:476-481.

23. Taylor S, Barragan A, Su C, Fux B, Fentress SJ, Tang K, Beatty WL, Hajj HE, Jerome M, Behnke MS, White M, Wootton JC, Sibley LD: A secreted serinethreonine kinase determines virulence in the eukaryotic pathogen Toxoplasma gondii. Science 2006, 314:1776-1780.

24. Blader IJ, Saeij JP: Communication between Toxoplasma gondii and its host: impact on parasite growth, development, immune evasion, and virulence. APMIS 2009, 117:458-476

25. Saeij JP, Boyle JP, Coller S, Taylor S, Sibley LD, Brooke-Powell ET, Ajioka JW Boothroyd JC: Polymorphic secreted kinases are key virulence factors in toxoplasmosis. Science 2006, 314:1780-1783.

26. Gibney EH, Kipar A, Rosbottom A, Guy CS, Smith RF, Hetzel U, Trees AJ, Williams DJ: The extent of parasite-associated necrosis in the placenta and foetal tissues of cattle following Neospora caninum infection in early and late gestation correlates with foetal death. Int J Parasitol 2008, 38:579-588.

27. Bartley PM, Wright S, Sales J, Chianini F, Buxton D, Innes EA: Long-term passage of tachyzoites in tissue culture can attenuate virulence of Neospora caninum in vivo. Parasitology 2006, 133:421-432.

28. Hemphill A, Gottstein B, Kaufmann H: Adhesion and invasion of bovine endothelial cells by Neospora caninum. Parasitology 1996, 112:183-197.

29. Mital J, Schwarz J, Taatjes DJ, Ward GE: Laser scanning cytometer-based assays for measuring host cell attachment and invasion by the human pathogen Toxoplasma gondii. Cytometry A 2006, 69:13-19.

30. Alvarez-Garcia G, Pitarch A, Zaballos A, Fernandez-Garcia A, Gil C, GomezBautista M, Aguado-Martinez A, Ortega-Mora LM: The NcGRA7 gene encodes the immunodominant $17 \mathrm{kDa}$ antigen of Neospora caninum. Parasitology 2007, 134:41-50

31. Collantes-Fernandez E, Zaballos A, Alvarez-Garcia G, Ortega-Mora LM: Quantitative detection of Neospora caninum in bovine aborted fetuses and experimentally infected mice by real-time PCR. J Clin Microbiol 2002, 40:1194-1198.

32. Hemphill A, Vonlaufen N, Naguleswaran A: Cellular and immunological basis of the host-parasite relationship during infection with Neospora caninum. Parasitology 2006, 133:261-278.

33. Plattner F, Soldati-Favre D: Hijacking of host cellular functions by the Apicomplexa. Annu Rev Microbiol 2008, 62:471-487.

34. Santos JM, Lebrun M, Daher W, Soldati D, Dubremetz JF: Apicomplexan cytoskeleton and motors: key regulators in morphogenesis, cell division, transport and motility. Int I Parasitol 2009, 39:153-162.

35. Naguleswaran A, Muller N, Hemphill A: Neospora caninum and Toxoplasma gondii: a novel adhesion/invasion assay reveals distinct differences in tachyzoite-host cell interactions. Exp Parasitol 2003, 104:149-158.

36. Vonlaufen N, Guetg N, Naguleswaran A, Muller N, Bjorkman C, Schares G, von Blumroeder D, Ellis J, Hemphill A: In vitro induction of Neospora caninum bradyzoites in vero cells reveals differential antigen expression, localization, and host-cell recognition of tachyzoites and bradyzoites. Infect Immun 2004, 72:576-583.

37. Behrendt JH, Taubert A, Zahner H, Hermosilla C: Studies on synchronous egress of coccidian parasites (Neospora caninum, Toxoplasma gondii, Eimeria bovis) from bovine endothelial host cells mediated by calcium ionophore A23187. Vet Res Commun 2008, 32:325-332.

38. Nischik N, Schade B, Dytnerska K, Dlugonska H, Reichmann G, Fischer HG: Attenuation of mouse-virulent Toxoplasma gondii parasites is associated with a decrease in interleukin-12-inducing tachyzoite activity and reduced expression of actin, catalase and excretory proteins. Microbes Infect 2001, 3:689-699.

39. Vianna MC, Sreekumar C, Miska KB, Hill DE, Dubey JP: Isolation of Neospora caninum from naturally infected white-tailed deer (Odocoileus virginianus). Vet Parasitol 2005, 129:253-257.

40. Sundermann CA, Estridge BH: Growth of and competition between Neospora caninum and Toxoplasma gondii in vitro. Int J Parasitol 1999, 29:1725-1732.

41. Diab MR, El-Bahy MM: Toxoplasma gondii: virulence of tachyzoites in serum free media at different temperatures. Exp Parasitol 2008, 118:75-79.

42. Long MT, Baszler TV, Mathison BA: Comparison of intracerebral parasite load, lesion development, and systemic cytokines in mouse strains infected with Neospora caninum. J Parasitol 1998, 84:316-320.

43. Collantes-Fernandez E, Alvarez-Garcia G, Perez-Perez V, Pereira-Bueno J, Ortega-Mora LM: Characterization of pathology and parasite load in outbred and inbred mouse models of chronic Neospora caninum infection. J Parasito/ 2004, 90:579-583.

44. Lopez-Perez IC, Risco-Castillo V, Collantes-Fernandez E, Ortega-Mora LM: Comparative effect of Neospora caninum infection in BALB/c mice at three different gestation periods. J Parasitol 2006, 92:1286-1291.

45. Pinitkiatisakul S, Mattsson JG, Lunden A: Quantitative analysis of parasite DNA in the blood of immunized and naive mice after infection with Neospora caninum. Parasitology 2008, 135:175-182.

46. Innes EA, Wright S, Bartley P, Maley S, Macaldowie C, Esteban-Redondo I, Buxton D: The host-parasite relationship in bovine neosporosis. Vet Immunol Immunopathol 2005, 108:29-36.

47. Collantes-Fernandez E, Rodriguez-Bertos A, Arnaiz-Seco I, Moreno B, Aduriz G, Ortega-Mora LM: Influence of the stage of pregnancy on Neospora caninum distribution, parasite loads and lesions in aborted bovine foetuses. Theriogenology 2006, 65:629-641.

48. Sibley LD, Mordue DG, Su C, Robben PM, Howe DK: Genetic approaches to studying virulence and pathogenesis in Toxoplasma gondii. Philos Trans R Soc Lond B Biol Sci 2002, 357:81-88.

49. El Hajj H, Lebrun M, Arold ST, Vial H, Labesse G, Dubremetz JF: ROP18 is a rhoptry kinase controlling the intracellular proliferation of Toxoplasma gondii. PLoS Pathog 2007, 3:e14

50. Barber JS, Holmdahl OJ, Owen MR, Guy F, Uggla A, Trees AJ: Characterization of the first European isolate of Neospora caninum (Dubey, Carpenter, Speer, Topper and Uggla). Parasitology 1995, 111:563-568

doi:10.1186/1297-9716-42-41

Cite this article as: Regidor-Cerrillo et al:: In vitro invasion efficiency and intracellular proliferation rate comprise virulence-related phenotypic traits of Neospora caninum. Veterinary Research 2011 42:41.

\section{Submit your next manuscript to BioMed Central and take full advantage of:}

- Convenient online submission

- Thorough peer review

- No space constraints or color figure charges

- Immediate publication on acceptance

- Inclusion in PubMed, CAS, Scopus and Google Scholar

- Research which is freely available for redistribution

Submit your manuscript at www.biomedcentral.com/submit
C Biomed Central 